\title{
THINK FUZZY SYSTEM: DEVELOPING NEW Pricing Strategy Methods For Consumer GOODS USING FUZZY LOGIC
}

\author{
Antonio Morim ${ }^{*}$, Eduardo Sá Fortes ${ }^{*}$, Paulo Reis ${ }^{+}$, Carlos Cosenza ${ }^{+}$, Francisco \\ Doria $^{+}$, Armando Gonçalves ${ }^{+}$ \\ * Production Engineering Master's Program, Federal University of Rio de Janeiro, \\ Instituto Alberto Luiz Coimbra de Pós-Graduação e Pesquisa de Engenharia ,COPPE, \\ Bloco G, Ilha do Fundão, 21945-970, Rio de Janeiro - Brasil
}

\begin{abstract}
The main purpose of this article is to present and explore potential applications in marketing administration related to pricingstrategyusingfuzzylogic. Considering the new trends in consumer behavior in Brazil's economy and the consistent growth of $C$ and D social classes an application was developed by the authors to better understand and adjust pricing strategies: The Think Fuzzy System that combines fuzzy logic (COPPE Cosenza Model), and some other related strategic concepts, supported by mathematical microeconomic modeling, utility factor, indifference curves and an experiential hierarchic clustering model.
\end{abstract}

\section{KEYWORDS}

Consumer behavior, think fuzzy system, fuzzy logic, pricing methods, microeconomic mathematical models

\section{INTRODUCTION}

The recent scenario in Brazil's economy, with no stability and a continuous economic recession, brought a new challenge related to $\mathrm{C}$ and $\mathrm{D}$ social classes: consumers with lessmoney to spend, adopting new habits.

The biggest challenge is to understand if past consumer behaviors and habits can be used to position and sell new consumer goods to these social classes in Brazil (DÓRIA, 2009).

The utility conceptdefines that, by observing a consumer's choices whether he or she was better off after a change in prices. The consumer revealed by choices what his or her preferences werehence the term "revealed preferences". (SAMUELSON 1997)

Marketing administration more and more try to improve new methods of analyzing consumer behavior, and new experiential aspects are taken into consideration. Researchers today's emphasis, are in studying the importance of consumer emotional answers as main aspects of their attitudes.(SOLOMON, 2002)

The macro consumer behavior is created by social issues but to reach the factors of micro consumer behavior, so called individual factors, the following indicators have to be considered: cultural anthropology, history, demography, semiotic/literary criticism, macroeconomics, sociology, social psychology, microeconomics, clinical psychology and experimental psychology ( SOLOMON et al.2006).

DOI : 10.5121/ijfls.2017.7101 
Also in a marketer's viewpoint, the psychology means that how, when and where people spend their own time and money, and also, it can show the effects of purchase on the identity, personality and lifestyle of customer as psychological variables. So, market segmentation should consider psychological variables (SARLI and TAT, 2011).

Also at one big challenge for the companies is to understand price elasticity of demand, because is crucial to figure out how changes in prices and demand can be related. Considering these new emerging social classes, should the companies adjust their actual products to these new customers in terms of kind of promotions and offers or should these companies develop specific solutions even creating new products supported by their strong brands.

Also in this context, is important to evaluate, if we can use the Utility Function, as a reference to consumer purchase understanding.

Consumers make purchase seven in times of economic recession, but depending on the size of the crisis as we have been facing in Brazil nowadays, for sure some factors have to be taken into consideration. For example, customers will not by products at higher prices if they understand that these products have not quality enough.

Changes of the social or economic situation can make changes in the consumer's purchase behavior. These purchases could be more purposeful, responsible and taking price into the most important aspect to consider.

In addition, marketing strategy should be able to be sensitive enough to understand the importance of capturing consumers' preferences that could affect products depending on their origin (ABIDIN,2016).

We could also into consideration, aspects related to local products that in certain moments can create images that could support consumer decision connecting some country specific values (SARLI,2011).

Technology products can have different patterns regarding purchase decision including for example lifestyle (CHANG,2015).

As a great deal of consumers has new budget lines, we can understand that new price elasticity demand curves can be created.

Also, considering that these new budget lines and differentdemand numbers can be generated. But what is going to happen if we increase production to answer to the market needs and do not keep prices in the same levels or change price strategy?(NAGLE, 1987), is there a possibility of raising the prices and the demand keep on growing among consumers that prefer this soft drink brand to others? How to prove or assure insome degree of certainty a new price elasticity demand curve?

\section{Pricing Decisions Using Fuzzy Logic}

As marketing actually intensifies its studies related to understand how attitudes and culture can influence purchase decisions by customers, some different studies also using fuzzy logic and looking for behavioral reactions of consumers appears (VALASKOVÁ, 2015) and (BAGOOZI, 1999) refers to the emotional decisions consumers can take when deciding purchases. (YOGI, 2015) explores a fuzzy logic approach to product quality and purchase intention of consumers in 
two wheelers. (ALAMGIR, 2010), analyses brand names influence in the consumerchoice. (GANIDEH,2011) express his ideas questioning if fuzzy logic can predict consumer ethnocentric tendencies. (NAEINI,2016) propose a specific research to understand if there is a form of prioritizing lifestyles in shopping centers, using fuzzy logic. (SLATEVA, 2011) proposes a model of intentionsthat considers a social CRM system.

\section{FUZZY DECISION SYSTEM}

As we show in Figure 1, we describe our fuzzy decision system.

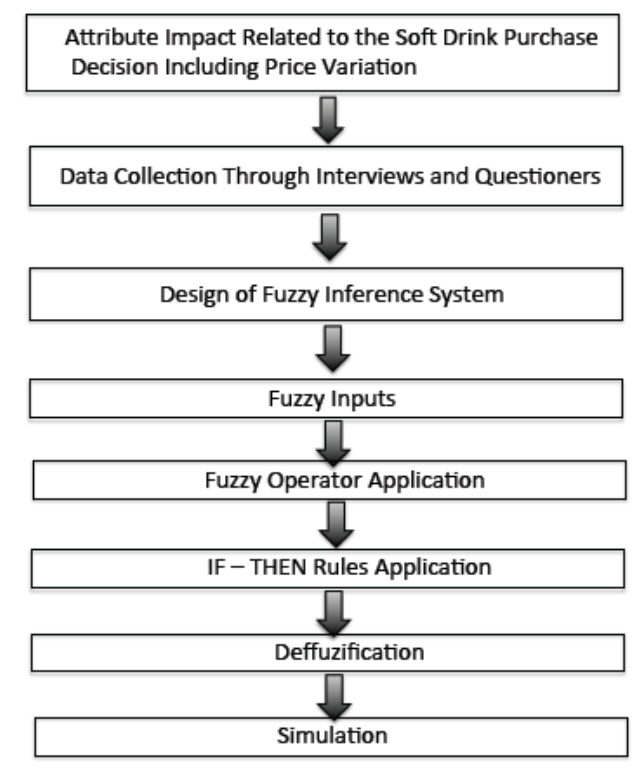

Figure 1 -Fuzzy Decision System

\section{FUZZY LOGIC}

Our every-day language is notably imprecise. We avoid absolutes and communicate by giving our audience a direction, a sense of what we mean. But it works! When we say: "This bald man is a frequent smoker," everyone understands: "Bald" refers to a quantity of hair somewhere between "balding" and "completely hairless"; "frequent smoker" is less than "chain smoker" and more than "occasional smoker." To better communicate our thoughts, we often confuse things a bit further: Saying a man is "bald" or a "frequent smoker" seems too absolute a characterization. He will, most likely, be "quite bald" and a "rather frequent smoker."

The vagueness of qualifiers "quite" and "rather "does not hinder communication. Imprecise language can best reflect human reality. Yet, when marketing began using computers, we were forced to precisely define the terms we use in order to make them acceptable to the computer. Thus a "frequent cigarette smoker" is defined, let's say, as one who smokes one pack or more per day, and a "bald man," as one having 5,000 hairs or less. In this precise world, the poor man who loses just one of his 5,001 hairs becomes instantly bald.

The one who regularly smokes 19 cigarettes' every day is not a frequent smoker.

A new mathematical tool is now available, which could help change all that: Introducing FUZZY 
LOGIC. Created by Professor LoftiZadeha former chairman of the electrical engineering and computer sciences department at the University of California at Berkeley.

To start with, a Fuzzy Logic definition of a frequent smoker would be "smokes about one pack or more a day." Then, rather than categorizing a given smoker as "frequent," the Fuzzy Logician would allocate it a coefficient (between 0 and 1) to indicate how well the smoker can be identified with the "frequent smokers" set. With 19 cigarettes per day, the coefficient could be .75 ; with 25 cigarettes, .95 , and so on. (ZADEH, 1975)

In other words, Fuzzy Logic reflects the way most of us speak, allowing for all the qualifiers one may use when talking about someone as a frequent smoker. When saying, "he is a rather frequent smoker," we do not give "rather" a meaning related to a certain number of cigarettes. We give our impression of how well the subject belongs to the group of "frequent smokers." We use "rather" as a fuzzy coefficient.

This theory has applicationsto marketing and advertising. It can enable the analysis of consumer answers, as imprecise as they naturally come. It should put an end to the "women 18 to 49 " target audience definition, which has no reason for being in fuzzy language (they'd probably become "young and middle-aged women"). It should improve our analysis of consumer emotions, where the language is often purposefully rendered vague with a plethora of qualifiers: In Fuzzy Logic, "extremely" can multiply "very" and one can take the square root of "few" or solve a problem like "if most student are rather frequent smokers, how many smoke frequently?"

The answer is "most" multiplied by "rather", of course.

So we can understand that in instead of using just probabilistic aspects related to qualitative and quantitative surveys to these customers and markets, we can also usea possibilistic logic approach, reorganizing these consumers in different types of clusters, considering behaviors and attitudes.

Triangular Fuzzy Numbers are a better way to demonstrate that fuzzy/possibility is about the range within the theoretical range but beyond observations.

Geometric figures like a triangle can demonstrate intervals in a better way. Intervals are numbers whose values are not know with certainty but about which bounds can be established. (Figures 2,3 e 4.(Klir,1995).

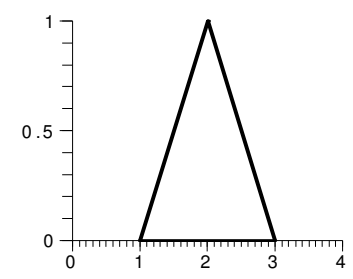

Figure 2 - Triangular fuzzy figure 


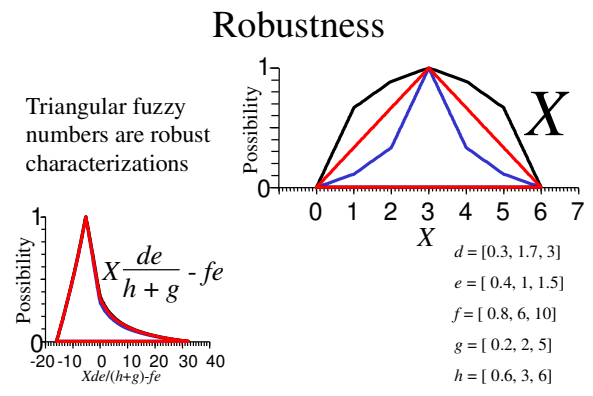

Figure 3 - interval demonstrations

In applications it is often convenient to work with triangular fuzzy numbers because of their computational simplicity, and they are useful in promoting representation and information processing in a fuzzy environment.

\section{DEFUZZIFICATION}

Among the many methods that have been proposed in the literature in recent years, seven are described here for defuzzifying fuzzy output functions.

1. Max membership principle:Also known as the heightmethod, this scheme is limited to peaked output functions. This method is given by the algebraic expression

$$
\mu_{\mathrm{C}}\left(z^{*}\right) \geq \mu_{\mathrm{C}}(z) \quad \text { for all } z \in Z
$$

Where $z^{*}$ is the defuzzified value, and is show graphically in Figure 4

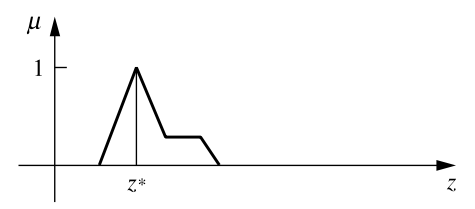

Figure 4 Max membership defuzzification method

2. Centroid method:This procedure (also called center of area, center of gravity) is the most prevalent and physically appealing of all the defuzzification methods; it is given by the algebraic expression

$$
z=\frac{\int \mu_{C}(z) \cdot z d z}{\int \mu_{C}(z) d z}
$$

Where $\int$ denotes an algebraic integration. This method is shown in Figure 5.

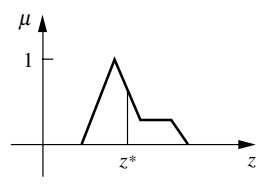

Figure 5 Centroid defuzzification method 
3. Weighted average method:The weighted average method is the most frequently used in fuzzy applications since it is one of the more computationally efficient methods. It is given by the algebraic expression

$$
z^{\square}=\frac{\sum \mu_{\mathrm{C}}(\bar{z}) \cdot \bar{z}}{\sum \mu_{\mathrm{C}}(\bar{z})}
$$

Where, $\sum$ denotes the algebraic sum and where $\bar{z}$ is the centroid of each symmetric membership function. This method is shown in Figure 6. The weighted average method,is formed by weighting each membership function in the output by its respective maximum membership value. As an example, the two functions shown in Figure 6 would result in the following general form for the defuzzified value:

$$
z^{\square}=\frac{a(0.5)+b(0.9)}{0.5+0.9}
$$

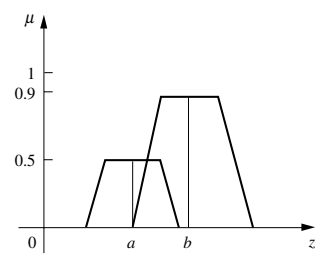

Figure 6 Weighted Average method of defuzzification

Since the method is limited to symmetrical membership functions, the values $a$ and $b$ are the means (centroids) of their respective shapes.

4. Mean max membership:This method (also called middle-of-maxima) is closely related to the first method, except that the locations of the maximum membership can be no unique (i.e., the maximum membership can be a plateau rather than a single point). This method is given by the expression;

$$
z=\frac{a+b}{2}
$$

Where, points a, and b are as defined in Figure7.

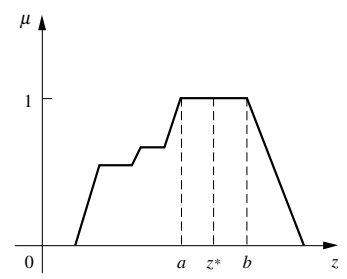

Figure 7 Mean max membership defuzzification method

5. Center of sums:This is faster than many defuzzification methods that are presently in use, and the method is not restricted to symmetric membership functions. This process involves the algebraic sum of individual output fuzzy sets, say $\mathbf{C}, \mathbf{C}_{2}$, instead of their union. Two drawbacks to this method are that the intersecting areas are added twice, and the method also involves 
finding the centroids of the individual membership functions. The defuzzified value $z$ is given by the following equation:

$$
z=\frac{\int_{z} \bar{z} \sum_{k=1}^{n} \mu_{C_{k}}(z) d z}{\int_{z} \sum_{k=1}^{n} \mu_{C_{k}}(z) d z}
$$

where the symbol $\bar{z}$ is the distance to the centroid of each of the respective membership functions.

This method is similar to the weighted average method, except in the center of sums method the weights are the areas of the respective membership functions whereas in the weighted average method the weights are individual membership values. Figure 8 is an illustration of the center of sums method.

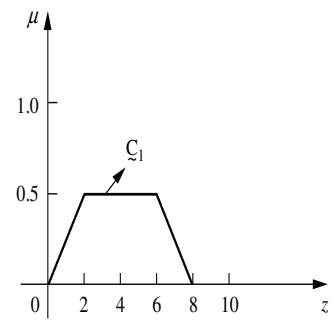

(a)

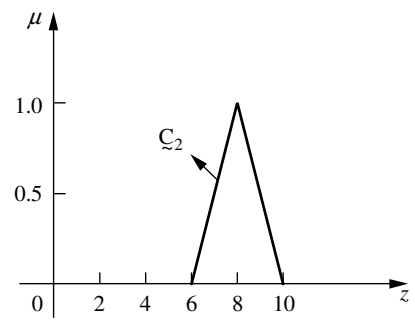

(b)

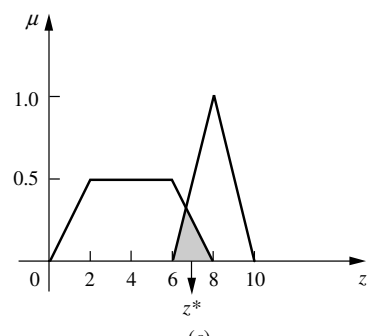

(c)

FIGURE 8 Center of sums method: (a) first membership function; (b) second membership function; and (c) defuzzification step

6. Center of largest area:If the output fuzzy set has atleast two convex subregions, then the center of gravity (i.e., $Z$ is calculated using the centroid method, Eq. of the convex fuzzy subregion with the largest area is used to obtain the defuzzified value $Z$ of the output. This is shown graphically in Figure 8 and given algebraically here: 


$$
z=\frac{\int \mu_{C_{m}}(z) z d z}{\int \mu_{C_{m}}(z) d z}
$$

Where, $C_{m}$ is the convex subregion that has the largest area marking up as $C_{k}$. This condition

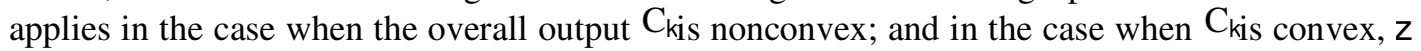
is the same quantity as determined by the centroid method or the center of largest area method (because then there is only one convex region).

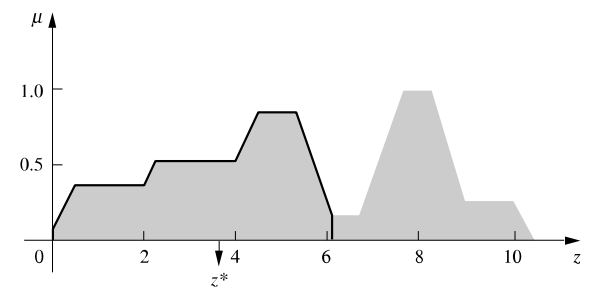

Figure 9 Center for largest area method (outlined with bold lines), shown for a nonconvex $C_{k}$

7. First (or last) of maxima:This method uses the overall output or union of all individual output fuzzy sets to determine the smallest value of the domain with maximized membership degree in. The equations for are as follows.

First, the largest height in the union (denote hgt) is determined,

$$
\operatorname{hgt}\left(C_{k}\right)=\sup _{z \in Z} \mu_{C_{k}}(z)
$$

Then the first of the maxima is found,

$$
z *=\inf _{z \in \mathrm{Z}}\left\{z \in \mathrm{Z} \mid \mu_{\mathrm{C}_{k}}(z)=\operatorname{hgt}\left({\underset{\sim}{k}}_{k}\right)\right\}
$$

An alternative to this method is called the last of maxima, and it is given by

$$
z^{*}=\sup _{z \in Z}\left\{z \in Z \mid \mu_{\mathcal{C}_{k}}(z)=\operatorname{hgt}\left({\underset{\sim}{k}}_{k}\right)\right\}
$$

In the above Equations the supremum (sup) is the least upper bound and the infimum (inf) is the greatest lower bound. Graphically, this method is shown in Figure 10, where, in the case illustrated in the figure, the first max is also the last max and, because it is a distinct max, is also the mean max.

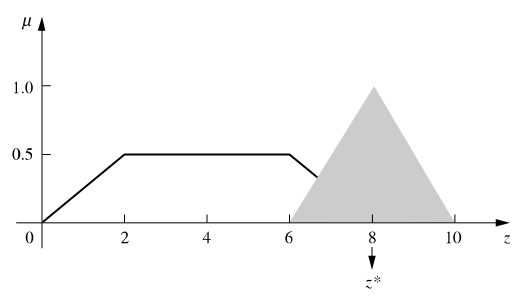

Figure 10 First of Max(and last of Max) method 
International Journal of Fuzzy Logic Systems (IJFLS) Vol.7, No.1, January 2017

\section{Consumer Choice And Decision Making: Problem Recognition.}

One model of consumer decision-making involves several steps. First, the problem recognitionthe way a person realizes that something is not as it should be. One example, your car is getting more difficult to start and is not accelerating well. The second step is information search-what are some alternative ways of solving the problem?The third step involves evaluation ofalternatives Finally, we have the purchase stage, and sometimes a post-purchase stage Consumers may go back and forth between the stages.

(Kotler, 2012), consumer involvementwill tend to vary dramatically depending on the type of product. In general, consumer involvement will be higher for products that are very expensive (e.g., a home, a car) or are highly significant in the consumer's life in some other way (e.g., a word processing program or acne medication).

It is important to consider the consumer's motivation for buying products. To achieve this goal, we can use the Means-End chain, wherein we consider a logical progression of consequences of product use that eventually lead to desired end benefit. Thus, for example, a consumer may see that a car has a large engine, leading to fast acceleration, leading to a feeling of performance, leading to a feeling of power, which ultimately improves the consumer's self-esteem.

\section{INFORMATION SEARCH AND DECISION-MAKING}

Consumers engage in both internal and externalinformation search. Internalsearch involves the consumer identifying alternatives from his or her memory. For certain low involvement products, it is very important that marketing programs achieve "top of mind" awareness. For example, few people will search webfor fast food restaurants; thus, the consumer must be able to retrieve one's restaurant from memory before it will be considered.

For high involvement products, consumers are more likely to use an externalsearch. Before buying a car, for example, the consumer may ask friends' opinions, read reviews in Consumer Reports, consult several web sites, and visit several dealerships. Thus, firms that make products that are selected predominantly through external search must invest in having information available to the consumer in need-e.g., through brochures, web sites, or news coverage.

A compensatory decision involves the consumer "trading off" good and bad attributes of a product. Occasionally, a decision will involve a non-compensatorystrategy. For example, a parent may reject all soft drinks that contain artificial sweeteners. Here, other good features such as taste and low calories cannotovercome this one "non-negotiable" attribute.

The amount of effort a consumer puts into searching depends on a number of factors such as the market (how many competitors are there, and how great are differences between brands expected to be?), product characteristics (how important is this product? How complex is the product? How obvious are indications of quality?), consumer characteristics (how interested is a consumer, generally, in analyzing product characteristics and making the best possible deal?), and situationalcharacteristics (as previously discussed).

A number of factors involve consumer choices. In some cases, consumers will be more motivated. Some consumers are also more motivated to comparison shop for the best prices, while others are more convenience oriented. Personality impacts decisions. Some like variety more than others, and some are more receptive to stimulation and excitement in trying new stores. Perception influences decisions. Some people, for example, can taste the difference between generic and name brand foods while many cannot. Some consumers are put off by 
perceived risk, others will tend to change their behavior through learning, they will avoid for example products that are not sustainable.

\section{MARKet Demand Elasticity}

The profit maximization $(\mathrm{P})$ implies that marginal revenue should equal marginal cost (MC), which in turn implies:

$\mathrm{P}-\mathrm{MC} 1 \mathrm{P} \quad=-\mathrm{E} \quad(1)$

Ed, is the firm's price elasticity of demand. Note that this equation can be rewritten as:

$\mathrm{P}=\mathrm{MC}(2) 1+(1 / \mathrm{Ed})$

If the firm is a monopolist, then the relevant elasticity is the market elasticity of demand, which I will denote by Ed. Obtaining an estimate of this market elasticity of demand may or may not be difficult, but for the moment, let's assume that we have such an estimate. Given this estimate of Ed, how can we obtain an estimate of the firm's price elasticity of demand, Ed.

If we assume that the firms in the market compete using Cournot model (which may or may not be a reasonable assumption), obtaining the elasticity of demand for an individual firm is fairly straightforward. Suppose that there are $\mathrm{n}$ equal-sized firms in the market, and that they all have the same marginal cost, c. In the Cournot model, each firm chooses its profit- maximizing output taking the outputs of its competitors as fixed.

We know that in many industries firms use price as a strategic variable, rather than quantity. The use of price rather than quantity as a strategic variable intensifies competition and reduces profits. This means that the effective elasticity of demand for a particular brand is likely to be larger in magnitude than the Cournot model would predict. Howmuch larger? That depends on the crossprice elasticities among the different brands. (Pindyck, 2009)

If the cross-price elasticities are large (for example the brands are fairly close substitutes), the Cournot analysis won't work: Ed is likely to be much larger than nEd. If, on the other hand, substitutability among brands is limited, the Cournot result will likely still hold.

Remember that the Cournot model is essentially static; it assumes that each firm takes the output of its competitors as fixed. As explained above, this assumption is quite reasonable for the large number of markets where competition is stable and dynamic price wars are generally avoided. This kind of stable pricing could arise if the same firms having been competing for a long time (and there is little prospect of entry by new firms), production cost and market demand conditions are relatively stable, and the firms face a repeated Prisoners' Dilemmawith no end point (and thus little or no likelihood of "unravelling"). But the Cournot assumption will not be reasonable for markets where pricing and output decisions are dominated by dynamic gaming considerations.

Airlines. One example is airlines, where very low short-run marginal costs result in intense price competition, particularly for certain fare categories. As you have seen, airline pricing is also complicated by the fact that prices are linked to yield management (i.e., the allocation, which changes from day to day, of the number of seats for each fare category). What can an airline do to avoid the intense price competition that is so prevalent in the industry? As we have discussed, one strategy is seek and maintain "monopoly routes," where it is the only airline to offer non-stop service. 
Price competition becomes intense well before that date as stores face the unhappy prospect of being stuck with large amounts of unsold inventories that they will have to dump, often at below cost. Over the years, managers of large retail chains and department stores have become increasingly sophisticated in their understanding of game theory. What has this done for them? The result is that they are more aware of the unravelling problem, and they are aware that their competitors are also aware of the problem. Thus they anticipate that the unravelling will start earlier.

Not wanting to be the "sucker" who gets undercut and winds up with lots of unsold inventories, each storetries to get a jump on the unravelling. And as you would expect, the unravelling starts earlier. Ten years ago the unravelling generally began on or just after Thanksgiving, five years ago in mid-November, and in more recent years unravelling has started by the beginning of November. If you ran a retail store chain, how should you go about setting prices? First of all, you are stuck in a bad place and deserve a lot of sympathy! Beyond that, the best you can do try to predict when and how the unravelling is likely to occur, make sure you are not on vacation or asleep when it starts, and take it into account when you determine the quantities that you will purchase at wholesale.

\section{Soft Drink Industry}

A nice thing about industries such as beer, soft drinks, breakfast cereals, airlines, auto-mobiles, etc., is that they have been around for a long time, and a good deal of data are available so that we can estimate market demand curves. Often, however, firms must set the prices of new products for which there is little or no history of demand or consumer response to price changes.

\section{A Practical Application}

We took as an example to study the initial aspects related to attitudes and behaviors of consumers when consuming five different types of, soft drinks, juices and water produced by a well-known brand in Brazil.

We applied the two methods:

The normal statistic approach conducting first a qualitative survey and after that a quantitative survey taking all the parameters that are recommended in terms of amostral size, trust factor, standard deviation, but also with the same consumers we conducted a new type of survey that considers fuzzy aspects and a experimental hierarchic clustering model.

For the fuzzy aspects we applied the COPPE Cosenza Model, developed at Centre for Higher Studies in Fuzzy Logic (LABFUZZY) at Universidade Federal do Rio de Janeiro (UFRJ) (COSENZA, 1981).

The hierarchic clustering model applied is a technique that serves to combine objects to create new groups, it can be used to group variables, objects or people. The inputs are any valid measures of correlations between these objects, also the numbers of clusters or the level of clustering can be the inputwe can start with all objects in one cluster and divide and subdivide then until all objects are in their own single-object cluster applying the Think Fuzzy System to this of clustering model we can achieve different sub clusters (a cluster inside a cluster) based on the distance between the group centroid (the centroid is the point whose coordinates are the icons of all the observation in the specific cluster) (AAKER, 2009). 
The consumers where asked to say their opinions, related to 9 important attributes of this soft drink.

The attributes were: price, quality, brand, health habit, tasty, practical, package, promotion campaigns andlife of the product concerns.

The explanations below will be related only to the price aspects studied, but nevertheless the figures 10 and 11 will demonstrate the opportunities found when comparing crispy and fuzzy results in all attributes that we had contemplated in the survey.

In the first survey, that we called crispy research, we asked to the consumers to give from 1 to 5 , considering 5 and the biggest importance and considering 1 as the lowest importance to each attribute detailed above.

In the second survey, that we called fuzzy research, we asked to the consumers, to give 5 concepts as detailed below, related to the importance of each attribute:

Very important, important, indifferent,less relevant and irrelevant.

We have done 660 individual surveys crispy and fuzzy with the same persons. The trust factor utilized was $95 \%$, with $4 \%$ error margin. The actual Rio de Janeiro population, according to IBGE (Instituto Brasileiro de Geografia e Estatística), official Institute to this subject in Brazil, is almost 16 million people and 53\% are in social classes $\mathrm{C}$ and $\mathrm{D}$, primary target of this survey.

\section{SURVEY ASPECTS - PRICE}

We asked consumers that have the soft drink brand as their first preference what would be their opinion if there had to be a $10 \%$ increase in final prices to them, if this increase was or was not relevant enough to force them to reduce their purchase of the soft drink.

We collected data in the crispy form, with possible answers from 1 to 5 , being 1 the lowest one or and 5 the highest score.

With the same customers we collected data in the fuzzy form with linguistic expressions from irrelevant to very important as described above.

Initially we organize them in 5 customer behavioral clusters depending on their evaluation to this question, from 1 to 5. Taking a deep look in the fuzzy survey final results we have concluded that part of the customers that had answered the crispy survey with a grade 3, had to be considered as significant to the decision of raising prices because with linguistic answers they demonstrated some relevancy to the topic.

So from now on to next analysis we will consider six behavioral clusters, considering the cluster with the answer indifferent, in two definitions: indifferent and less indifferent.

\section{Crispy Survey Results - Price}

\begin{tabular}{|l|l|l|l|l|l|}
\hline PRICE & $\begin{array}{l}\text { NOT } \\
\text { RELV }\end{array}$ & $\begin{array}{l}\text { LESS } \\
\text { RELV }\end{array}$ & INDIF & IMP & $\begin{array}{l}\text { VERY } \\
\text { IMP }\end{array}$ \\
\hline TOTAL & 10 & 60 & 290 & 193 & 117 \\
\hline
\end{tabular}

Table 1 - Amount of survey answers by type 


\section{FUZZIFICATION,DEFUZZIFICATION}

\begin{tabular}{|l|l|l|l|}
\hline & INDIF & IMPORT & VERY IMP \\
\hline 1 & 1 & 0 & 0 \\
\hline 2 & 1 & 0 & 0 \\
\hline 3 & 1 & 1 & 0 \\
\hline 4 & 0 & 1 & 1 \\
\hline 5 & 0 & 0 & 1 \\
\hline
\end{tabular}

Table 2 - Pertinence for a classic set

\begin{tabular}{|l|l|l|l|}
\hline & INDIF & IMPORT & VERY IMP \\
\hline 1 & 1 & 0 & 0 \\
\hline 2 & 0,6 & 0 & 0 \\
\hline 3 & 0,1 & 1 & 0,5 \\
\hline 4 & 0 & 0,5 & 1 \\
\hline 5 & 0 & 0,3 & 1 \\
\hline
\end{tabular}

Table 3 - Pertinence for a fuzzy set Fuzzy Triangular Numbers

$\mu=\min (\mu \mathrm{a}, \mu \mathrm{b}, \mu \mathrm{c}) ; \mu=\max (\mu \mathrm{a}, \mu \mathrm{b}, \mu \mathrm{c})$

$\mathrm{a}=$ indifferent; $\mathrm{b}=$ important; $\mathrm{c}=$ very important

$\mu \operatorname{tri}(x ; a, b, c)=\max (\min (x-a / b-a, c-x / c-b), 0)$, for $a<b<c$.

Indifferent $=(1,0),(2,0.6),(3,0.1)$,

$(4,0),(5,0)$

Important $=(1,0),(2,0),(3,1),(4,0.5),(5,0.3)$

Very Important $=(1,0),(2,0),(3,0.5)$

$(4,1),(5,1)$

Min $=(1,0),(2,0),(3,0.5),(4,0.5),(5,0.3)$

$\operatorname{Max}=(1,0),(3,0),(3,1),(4,1),(5,1)$

\section{DEFFUZIFICATION CHOICE - WeIgHTEd AVERAgE METHOD}

$\mu(\operatorname{output}(\mathrm{u})=\mu(\mathrm{a}) \nabla \mu(\mathrm{b})(\mathrm{u})$

$(3 \times 0+3,5 \times 0,3+4 \times 0,5+4,5 \times 0) /(0,3+0,5)=3,66$

So, $\mathbf{3 , 6 6}$ is the crisp number after deffuzification.

In figures 10 and 11 you can see and compare price results as well the other attributes.

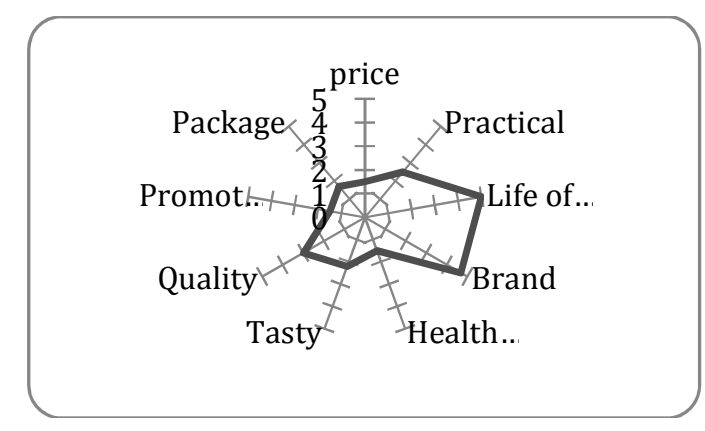

Figure 10 - crispy survey 


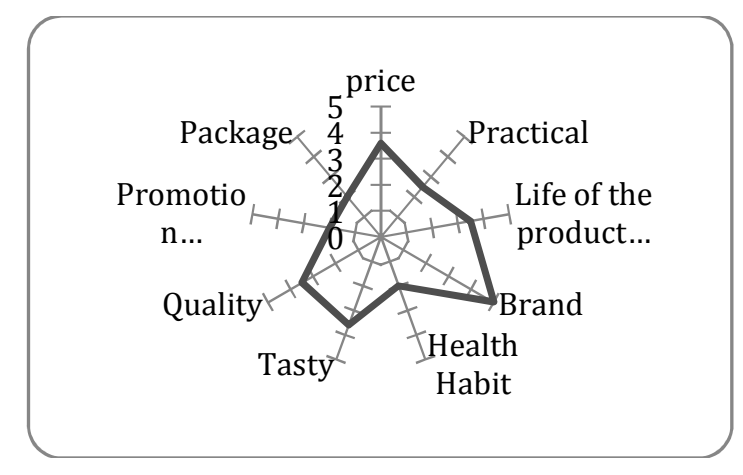

Figure 11 - fuzzy survey

In figure 10 we can see the fuzzy results, compared to the results in figure 11 related to the crispy survey. Notice thatprice had a significant difference. This difference shows in this particular analysis, that more consumers really understands that an increase of $10 \%$ or more, is very important, also just looking for the other attributes we can understand that there is plenty of space to a more detailed analysis.

\section{CONCLUSION}

As a preliminary analysis we can see that the use of fuzzy logic supporting marketing decisions related to consumer habits and attitudes is important and can amplify the way the consumer can be understood. We entitled this method as Think Fuzzy System. As mentioned before, we applied it to all attributes referred in the survey.

Also looking for the micro economic aspects, like price strategy, and decisions related to elasticity price on demand, fuzzy logic can be used to look for some opportunities.

The example of the positive or negative impact of price elasticity in strategic decisions was to turn tangible the density in which this hybrid tool can be worked. Through the same approach (COPPE Cosenza Model + Think Fuzzy) it would be possible to monitor, identify and delineate critical issues, fundamental to the understanding of how community needs are being met or how certain infrastructural issues are being neglected, such as sustainability for example.

The most import is for sure demonstrate that nowadays when customer decisions are been taken at web speed and the moments of truth multiply their strength,corporations need more than just probabilistic tools to understand in depth how consumer attitudes can support better branding strategy and also improve consumer loyalty to their products and services depending on how they demonstrate credibility concerning their actions.

Looking for possible future research using our proposed Think Fuzzy System, we will conduct a research related to electronic commerce and predictive pricing strategy.Alsoa research related to purchases that keep its traditional aspects regarding been done by new consumer generations.

\section{BIBLIOGRAPHY}

[1] ALAMGIR, M., et al.Influence of brand name on consumer decision making process - an empirical study on car buyers (2010). Ann. "Ştefancel Mare" Univ. Suceava. Fascicle Fac. Econ. Public Admin., 10 (2) (2010), pp. 142-153; 
[2] BAGOOZI, et al. (1999). The role of emotions in marketing. Journal of Academic Marketing Science, 27 (2) (1999), pp. 184-206

[3] BIDIN, NUZARARHIA et al (2016);7th. International Economics \& Business Management Conference;

[4] AAKER, David A.(2009), Marketing Research; Wiley \& Sons, New York;

[5] CHANG .C.,(2015). A hybrid decision-making model for factors influencing the purchase intentions of technology products: the moderating effect of lifestyle. Behaviour \& Information Technology . Volume 34, Issue 12;

[6] COSENZA, Carlos A. (2011), Notas de aula disciplina - Introdução à Lógica Fuzzy - COPPE UFRJ; Rio de Janeiro;

[7] COSENZA, Carlos A. (1981), - "A Industrial Location Model"- Working paper, Martin Centre for Architectural and Urban Studies, Cambridge University

[8] DORIA, Francisco, A. (2011) - Notas de aula disciplina- Limites Computacionais e Modelagem Matemática - COPPE - UFRJ; Rio de Janeiro;

[9] DORIA, Francisco A. \& COSENZA, Carlos A. (2009), Crise na Economia. Editora Revan, Rio de janeiro;

[10] GANIDEH, S. et al, 2011. Can Fuzzy Logic Predict Consumer Ethnocentric Tendencies? An Empirical Analysis in Jordan. Journal of Physical Science and Application, 100-106;

[11] HENDERSON, James M. \& QUANDT, Richard E. (1968), Teoria Microeconomica - Uma Abordagem Matemática. Biblioteca Pioneira de Ciências Sociais, São Paulo;

[12] KOTLER P. (2012), Marketing Management, New Jersey, Simon \& Schuster Co.

[13] LAISoon, W., et al, (2013). Hybrid vehicle adoption - a conceptual study. J. Educ. Vocat. Res. 4 (6), $165 \mathrm{e} 168$.

[14] KLIR, George J.(1995)Fuzzy Sets and Fuzzy Logic: theory and applications. Prentice Hall, New Jersey;

[15] NAEINI, A. et al,(2016), Prioritizing Lifestyles in Shopping Centers, Using Fuzzy Logic Inference System ( Case Study: Shopping Centers in Zanjan). Intal Management Journal 67-76;

[16] PINDYCK, Robert S. (2009), Microeconomics. Prentice Hall,New Jersey;

[17] SAMUELSON, Paul A. (1997), Fundamentos da Análise, Editora Nova Cultural. São Paulo;

[18] SARLI, A. \&Tat, H(2011). Attracting Consumers by Finding out Their Psychographic Traits, International Journal of Fundamental Psychology \& Social Sciences, Vol 1, No.1, pp.6-10

[19] SOLOMON, Michael R. (2002), Consumer Behaviour: buying, having, and being. Prentice Hall, New Jersey;

[20] SOLOMON, Michael R.. et al. (2006). Consumer behavior: A Europeanperspective. England: Pearson Education Limited. 731 p.

[21] NAGLE, T., (1987). The Strategy \& Tactics of Pricing : A Guide to Profitable Decision Making, New Jersey. Prentice Hall.

[22] VALÁSKOVÁ, K., \& KLIESTIK, T., (2015). Behavioral Reactions of Consumers To Economic Recession. Journal Business: Theory and Practice, Slovakia;

[23] YOGI K.,(2015). An Empirical and Fuzzy Logic Approach to Product Quality and Purchase Intention of Customers in two Whelers, Pacific Science Review B: Humanities and Social Sciences, 57 -69;

[24] ZADEH, L.A. (1975), "The concept of a linguistic variable and its application to approximate reasoning", Parts 1 and 2, Information Sciences 8,199-249; 301-357;

[25] ZLATEVA, P. et al., A Model of Intention to Purchase as a Component of Social CRM System, 2011 International Conference on E-business, Management and Economics IPEDR Vol.25 (2011) (C) (2011) IACSIT Press, Singapore; 